\title{
ERRATUM
}

Alexandra Zhernakova $\cdot$ Peter Eerligh

Pilar Barrera · Joanna Z. Weseloy

Tom W. J. Huizinga - Bart O. Roep

Cisca Wijmenga - Bobby P. C. Koeleman

\section{CTLA4 is differently associated with autoimmune diseases in the Dutch population}

Published online: 8 December 2005

(C) Springer-Verlag 2005

\section{Hum Genet (2005) 118(1):58-66}

One of the authors of this article has been misspelled. J.Z. Weseloy should be J.Z. Wesoly.

The online version of the original article can be found at http:/ dx.doi.org/10.1007/s00439-005-0006-z

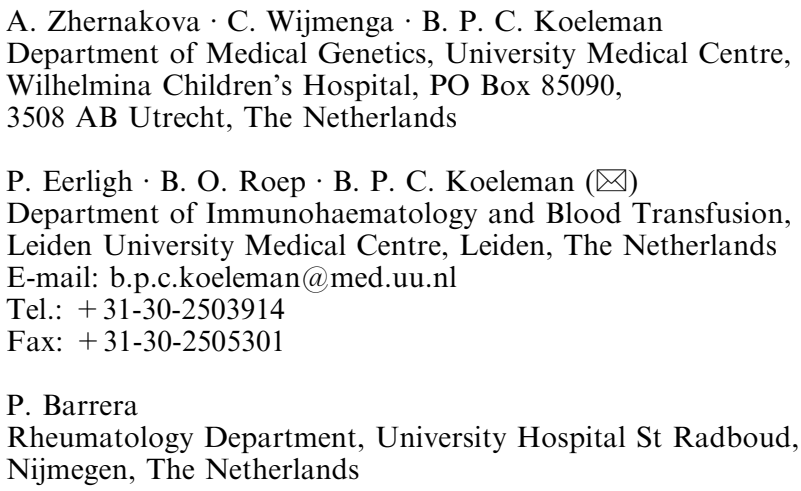

Department of Rheumatology, Leiden University Medical Centre, Leiden, The Netherlands 